\title{
Physiological Attributes for Screening of Indian mustard (Brassica juncea L. Czern and Coss) Genotypes during Terminal Heat Stress
}

\author{
Kavita $^{1 *}$ and Anil Pandey ${ }^{2}$ \\ ${ }^{1}$ Department of Botany and Plant Physiology, Faculty of Basic Sciences and \\ Humanities, DRPCAU, Pusa-848125 (Bihar), India \\ ${ }^{2}$ Department of Plant Breeding and Genetics, Tirhut College of Agriculture, Dholi, \\ Muzaffarpur-843121(Bihar), India \\ *Corresponding author
}

\section{A B S T R A C T}

Keywords

Brassica juncea, mustard, relative water content, membrane stability index, electrolyte leakage, heat stress

Article Info

Accepted:

26 August 2017

Available Online:

10 September 2017
A field experiment was conducted in Rabi 2015 in a randomized block design with the objective to screen advanced breeding lines (genotypes) of Indian mustard (Brassica juncea L. Czern and Coss) for different physiological parameters viz, chlorophyll content, membrane stability index (MSI \%), relative water content (RWC \%) and electrolyte leakage and yield related to terminal heat tolerance. The study indicated that genotypes, 'Pusa Bold', 'NRCHB-101' and 'PRO-5222' had tolerance to high temperature at terminal stage. The correlation coefficient between test weight of genotypes and chlorophyll content (0.843), MSI (0.832) and RWC (0.323) was positive but was negative for electrolyte leakage (- 0.564$)$.

\section{Introduction}

Rapeseed-mustard constitutes an important group of oilseed brassica crop, and is main source of edible oil next to soybean and groundnut in India. Rajasthan, Uttar Pradesh, Madhya Pradesh, Haryana, Gujarat and West Bengal states accounted for nearly $86.5 \%$ area and $91.4 \%$ production of rapeseed-mustard in the country during 2012-13. Indian mustard (Brassica juncea L. Czern and Coss) accounted for about $75-80 \%$ of the 6.6 million hectare under these crops during 2013-14 (DRMR, 2015). In North-Western part of India it accounts for about $80 \%$ of the cultivable area (Singh et al., 2014). It is grown under diverse agro ecological situations such as timely/ late sown, rainfed/ irrigated, sole- and/ or mixed crop with cereals and rabi pulses. The cultivation is largely carried out under the rainfed farming systems where sowing commences after south-west monsoon rains (Venkateswarlu and Prasad, 2012). Temperature stress is one of the major limitations to crop productivity worldwide. This crop is adversely affected by terminal stage 'heat stress' i.e. the sudden increase in ambient maximum temperature, in 
a matter of few days, by $5-7{ }^{\circ} \mathrm{C}$ with corresponding increase in the minimum temperature, that limits optimal plant performance. Flowering and grain filling are the most sensitive stages for temperature stress damage in Indian mustard probably due to vulnerability during pollen and grain development, anthesis and fertilization leading to reduced crop yield. It is likely that plants have evolved mechanisms through which cellular activity could be maintained at varying temperatures. More frequent weather aberrations and high temperature events are expected due to climate change scenario resulting in greater impact of heat on mustard production. Efforts to strengthen resilience are required by utilizing diverse heat tolerant genotypes in brassica crop improvement programmes. There is need to identify suitable screening indices that would facilitate the brassica crop improvement process for terminal heat tolerance. This will help to stabilize the productivity and to meet the growing demands of edible oil in the country. Therefore, the present study was conducted to screen advanced breeding lines of Indian mustard for different physiological parameters related to terminal heat tolerance.

\section{Materials and Methods}

Field experiment was conducted in Rabi 2015 with 14 advanced breeding lines in randomized block design (RBD) with four replications at Tirhut College of Agriculture, Dholi (2599'56' N, 8559'40', E, $52.12 \mathrm{~m}$ asl) research farm located in Muzaffarpur district of Bihar, India. Seeds of these advanced lines were received from the ICARDirectorate of Rapeseed-Mustard Research (ICAR-DRMR), Bharatpur, Rajasthan. The seeds were sown in five rows of $5 \mathrm{~m}$ length, with row to row and plant to plant spacing of $30 \mathrm{~cm}$ and $10 \mathrm{~cm}$, respectively. Sowing was done on $31^{\text {st }}$ November to expose the crop to high temperature during flowering.
Physiological parameters viz., chlorophyll content, leaf membrane stability index (MSI $\%$ ), relative water content (RWC \%), electrolyte leakage, and test weight (100seeds weight) were recorded. Leaf chlorophyll content was estimated by the method of Hiscox and Israelstam (1979). MSI was determined following the method of Sairam (1994) and RWC as described by Barrs (1968). Electrolyte leakage was determined following method based on in vitro desiccation of leaf tissues by a solution of polyethylene glycol (PEG) and a subsequent measurement of electrolyte leakage into deionised water (Bajji et al., 2002). Analysis of variance (ANOVA) was carried out to test the significance of treatment effect and least significant differences (LSDs) between means at $p \leq 0.05$ and the standard error (SE) of means were computed. Correlation coefficient between test weight and physiological parameters were determined following standard method (Gomez and Gomez, 1984).

\section{Results and Discussion}

Chlorophyll content in the different genotypes varied significantly from 4.83 to $9.06 \mathrm{mg} / \mathrm{g}$ fresh weight, the highest being in terminal heat stress tolerant genotype 'PRO-5222' and the lowest in susceptible genotype 'Pusa bold' (Table 1). Similar to our findings, Kumar and Srivastava (2003) had also suggested that tall genotype with medium bold seeds and high chlorophyll content was ideal for late sown conditions. MSI ranged from 7.09 to $37.05 \%$ highest being in the genotype 'PRO 5222'. Heat stress increases cell membrane permeability, thereby inhibiting cellular function, as a result of the denaturation of proteins and increments of unsaturated fatty acids that disrupt water, ion, and organic solute movement across membranes. Reduction in cell membrane stability under high temperature has also been reported in 
cowpea (Ismail and Hall, 1999). The results revealed a significant difference in RWC in Indian mustard genotypes. RWC of genotypes ranged from 52.28 (RGN 330) to $118.61 \%$ (PRO 5222) under heat stress conditions. Higher percent relative water content in leaves is a good indicator of heat resistance.

Our findings are in agreement with the earlier studies on Indian mustard by Ram et al., (2012) and Kumar et al., (2013). Electrolyte leakage ranged from $0.89 \%$ (PRO 5222) to $1.76 \%$ (RGN 330) highest being in the susceptible genotypes. This is frequently related to an increase in membrane permeability, affecting membrane integrity and cell compartmentation under stress conditions (Campos et al., 2003).

Reduction in test weight (1000-seed weight) occurred under terminal heat stress which varied significantly among genotypes and ranged between $3.11 \mathrm{~g}$ (Pusa Bold) to $5.57 \mathrm{~g}$
(PRO 5222). Though the test weight of 'Pusa Bold' was lowest, the seed yield was highest (1619 kg/ha). The highest temperature during reproductive phase (50 days prior to maturity) was between 24.5 to $33{ }^{\circ} \mathrm{C}$ (Fig. 1). The elevated temperature adversely affected yield of the crop. Angadi et al., (1999) had reported that the optimum daytime temperature for $B$. juncea cultivar was above $20^{\circ} \mathrm{C}$ and close to $28{ }^{\circ} \mathrm{C}$. Efficient photosynthetic response occurred at $15-20{ }^{\circ} \mathrm{C}$ temperature (Shekhawat et al., 2012). Heat stress during the postanthesis (seed filling) negatively influences the movement of photosynthetic products to the developing sinks and inhibits the synthetic processes, thus lowering seed weight and seed yield and may alter seed quality (Bhullar and Jenner, 1985). A low reduction in the physiological parameters like MSI, RWC and chlorophyll are some of the simple indices for screening and identifying heat stress tolerant genotypes as also suggested by Kumar et al., (2013).

Table.1 Physiological parameters related to terminal heat tolerance vis-à-vis yield of Indian mustard genotypes

\begin{tabular}{|l|c|c|c|c|c|c|}
\hline $\begin{array}{l}\text { Hybrid } \\
\text { Genotypes }\end{array}$ & $\begin{array}{c}\text { Chlorophyll } \\
\text { content (mg/g } \\
\text { fresh wt.) }\end{array}$ & MSI (\%) & $\begin{array}{c}\text { RWC } \\
(\%)\end{array}$ & $\begin{array}{c}\text { Electrolyte } \\
\text { leakage (\%) }\end{array}$ & $\begin{array}{c}\text { Test } \\
\text { weight } \\
(\mathrm{g})\end{array}$ & $\begin{array}{c}\text { Yield } \\
(\mathrm{kg} / \mathrm{ha})\end{array}$ \\
\hline Pusa Bold & 7.92 & 11.15 & 94.32 & 1.35 & 4.60 & 1146 \\
\hline Kranti & 6.94 & 35.37 & 90.77 & 1.24 & 4.52 & 1228 \\
\hline RH 923 & 7.37 & 25.73 & 84.38 & 1.36 & 3.94 & 1249 \\
\hline DRMR 1153-12 & 7.81 & 14.29 & 81.83 & 1.27 & 4.17 & 1196 \\
\hline DRMRIJ 13-38 & 8.00 & 18.55 & 85.58 & 1.24 & 4.71 & 860 \\
\hline JD 6 & 7.61 & 17.62 & 85.86 & 1.15 & 5.40 & 1042 \\
\hline Pusa Bold & 4.83 & 12.50 & 88.62 & 1.28 & 3.11 & 1619 \\
\hline RH 919 & 6.22 & 8.78 & 92.14 & 1.33 & 3.53 & 1331 \\
\hline RH 749 & 8.23 & 6.83 & 88.12 & 1.36 & 3.59 & 1114 \\
\hline RGN 337 & 6.97 & 15.11 & 90.08 & 1.28 & 3.87 & 1267 \\
\hline RGN 368 & 8.74 & 7.09 & 86.48 & 1.45 & 4.13 & 1050 \\
\hline NRCHB 101 & 8.80 & 17.84 & 84.36 & 1.15 & 5.39 & 1693 \\
\hline RGN 330 & 7.35 & 20.04 & 52.28 & 1.76 & 4.09 & 1167 \\
\hline PRO 5222 & 9.06 & 37.05 & 118.61 & 0.89 & 5.57 & 1362 \\
\hline LSD (p=0.05) & 0.34 & 0.62 & 0.60 & 0.23 & 0.81 & 273 \\
\hline SEm \pm & 0.01 & 0.22 & 0.21 & 0.08 & 0.28 & 11 \\
\hline
\end{tabular}


Fig.1 Daily mean maximum minimum temperature during reproductive phase at TCA, Dholi, Muzaffarpur

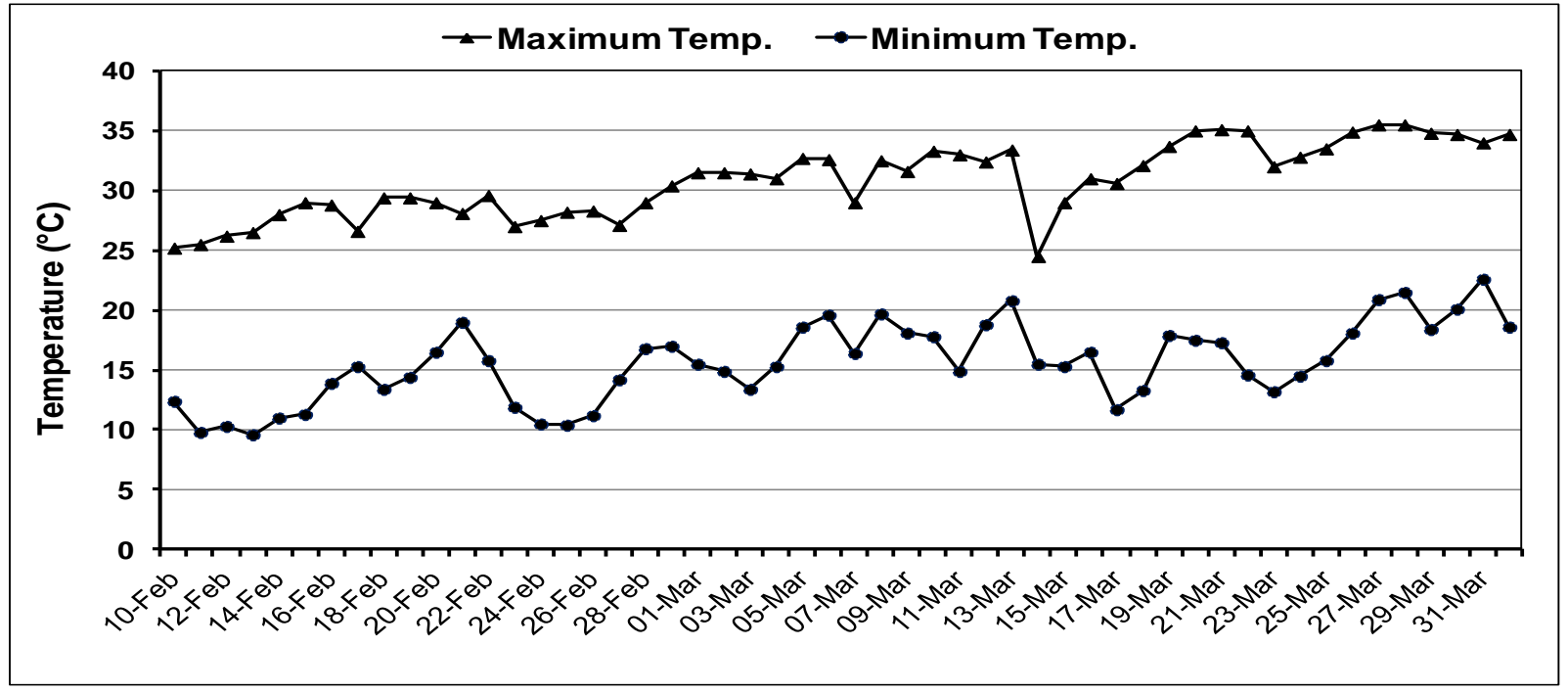

Fig.2 Correlation between test weight and different physiological traits of Indian mustard genotypes
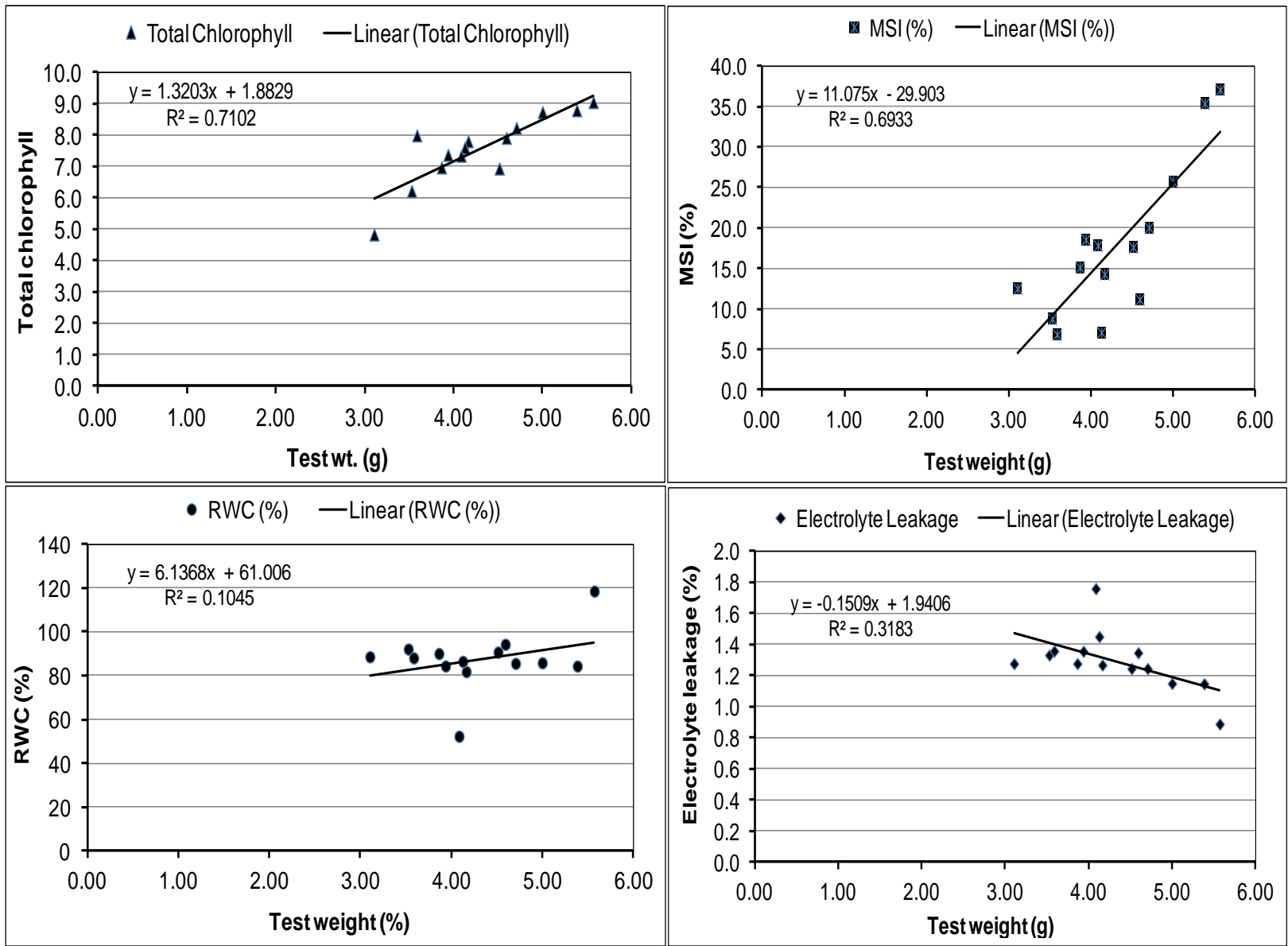
The significant co-efficient of correlation between test weight (1000-seed weight) and physiological traits were observed (Fig. 2). The correlation coefficient ' $r$ ' value was significant and positive for chlorophyll content $(0.843 * *), \operatorname{MSI}(0.832 * *)$ and RWC $\left(0.323^{*}\right)$ while it was negative for electrolyte leakage $(-0.564 * *)$. Similar correlation between seed yield and physiological traits had also been reported in Indian mustard by Ram et al., (2012) and Sharma and Sardana (2013). The present findings show that since the traits are highly correlated, selections based on correlations may be a useful for indirect selections for higher seed yield potential.

In conclusion, we report that the genotypes found best with respect to physiological traits vis-à-vis test weight and yield should be selected for late shown conditions where there is likelihood of terminal heat stress tolerance to plants. The study revealed that genotypes 'NRCHB-101' and 'PRO-5222' had tolerance to high temperature at terminal stage.

\section{References}

Angadi, S.V., Cutforth, H.W., Miller, P.R. and McConkey, B. 1999. Semiarid Prairie agricultural effect of high temperature stress on yield and yield components of three Brassica species. http://www.usask.ca/soilsncrops/confere nce-

proceedings/previous_years/Files/99/19 99docs/ 198.pdf.

Bajji, M., Kinet, J.M. and Lutts, S. 2002. The use of the electrolyte leakage method for assessing cell membrane stability as a water stress tolerance test in durum wheat. Plant Growth Regul, 36(1): 6170 .

Barrs, H.D., 1968. Determination of water deficits in plant tissues. In: Water deficits and plant growth Vol. 1 (Ed.)
T.T. Kozolvski. Academic Press, New Delhi. Pp. 235-368.

Bhullar, S.S., and Jenner, C.F. 1985. Differential responses to high temperature of starch and nitrogen accumulation in the grain of four cultivars of wheat. Aust. J. Plant Physiol., 12: 363-375.

Campos, P.S., Quartin, V., Ramalho, J.C. and Nunes, M.A. 2003. Electrolyte leakage and lipid degradation account for cold sensitivity in leaves of Coffea sp. Plants. J. Plant Physiol., 160: 283-292.

DRMR. 2015. Vision 2050. ICAR-Directorate of Rapeseed-Mustard Research, Bharatpur, Rajasthan, India. http://www.icar.org.in/Vision\%202050 \%20DRMR\%20Rajasthan.pdf.

Gomez, K.A., and Gomez, A.A. 1984. Statistical Procedures for Agricultural Research ( $2^{\text {nd }}$ edition), John Wiley and Sons, New York.

Hiscox, J.D., and Israelstam, G.F. 1979. A method for extraction of chlorophyll from leaf tissues without maceration. Can. J. Bot., 51: 1332-34.

Ismail, A.M., and Hall, A.E. 1999. Reproductive-stage heat tolerance, leaf membrane thermo-stability and plant morphology of cowpea. Crop Sci., 39: 1762-1768.

Kumar, N., and Srivastava, S. 2003. Plant ideotype of Indian mustard (Brassica juncea) for late sown conditions. Indian J. Genet., 63: 355.

Kumar, S., Sairam, R.K. and Prabhu, K.V. 2013. Physiological traits for high temperature stress tolerance in Brassica juncea. Indian J. Plant Physiol., 18: 8993.

Ram, B., Singh, B.K., Singh, M., Singh, V.V. and Chauhan, J.S. 2012. Physiological and molecular characterization of Indian mustard (B. juncea L.) genotypes for high temperature tolerance. Crop Improv. (Special Issue) ICSA, A-3: 5-6. 
Sairam, R.K., 1994. Effect of moisture stress on physiological activities of two contrasting wheat genotypes. Ind. $J$. Exp. Biol., 32: 593-594.

Sharma, P., and Sardana, V. 2013. Screening of Indian mustard (B. juncea) for thermo tolerance at seedling and terminal stage. J. Oilseed Brassica 4: 61-67.

Shekhawat, K., Rathore S.S., Premi O.P., Kandpal B.K. and Chauhan J.S. 2012. Advances in agronomic management of Indian mustard (Brassica juncea (L.)
Czernj.Cosson): An overview. Int. J. Agron., doi:10.1155/2012/408284.

Singh, V.V., Ram, B., Singh, M, Meena, M.L and Chauhan, J.S. 2014. Generation mean analysis for water stress tolerance parameters in Indian mustard [Brassica juncea (L.) Czern \& Coss] Crosses. SABRAO J. Breed. Genet. 46: 76-80.

Venkateswarlu, B., and Prasad, J.V.N.S. 2012. Carrying capacity of Indian agriculture: issues related to rainfed agriculture. Curr. Sci., 102: 882-888.

\section{How to cite this article:}

Kavita and Anil Pandey. 2017. Physiological Attributes for Screening of Indian mustard (Brassica juncea L. Czern and Coss) Genotypes during Terminal Heat Stress. Int.J.Curr.Microbiol.App.Sci. 6(9): 2908-2913. doi: https://doi.org/10.20546/ijcmas.2017.609.357 